\title{
CONTRIBUIÇÃO PARA A ALFABETIZAÇÃO CARTOGRÁFICA ATRAVÉS DO OBJETO DE APRENDIZAGEM DECIFRANDO OS MAPAS
}

Ana Giordani, Universidade Federal de Santa Maria - geo_giordani@yahoo.com.br Meri Lourdes Bezzi, Universidade Federal de Santa Maria - meri@oslo.ccne.ufsm.br

Roberto Cassol, Universidade Federal de Santa Maria - rtocassol@gmail.com

RESUMO:

Ao se apropriar das Tecnologias da Informação e Comunicação (TICs), a Geografia materializa os seus conteúdos didáticos, via objetos de aprendizagem, como instrumento auxiliar do processo ensino-aprendizagem, privilegiando a interatividade entre $\mathrm{o}$ educando e os saberes didáticos. Nesse sentido, esta pesquisa teve como foco central elaborar um objeto de aprendizagem sobre alfabetização cartográfica e validá-lo com os sujeitos do ensino e aprendizagem de Geografia. Como objetivos intrínsecos, tiveramse: (a) investigar práticas pedagógicas para o ensino e aprendizagem de Geografia, por meio de objeto de aprendizagem; (b) desenvolver e efetivar o objeto de aprendizagem em Geografia; (c) analisar a aplicação prática do objeto de aprendizagem na quinta série do Ensino Fundamental. Ressalta-se que o objeto de aprendizagem, desenvolvido em uma perspectiva interdisciplinar e interativa, de caráter construtivista, vem a contribuir como alternativa prática e viável, atraindo e motivando, com melhores resultados, à aprendizagem dos alunos. Os aspectos positivos desse recurso didático podem ser comprovados através da validação do objeto de aprendizagem junto aos alunos de quinta série do Ensino Fundamental.

Palavras-Chave: Tecnologias da Informação e Comunicação; Objetos de Aprendizagem; Alfabetização Cartográfica.

\section{CONTRIBUTION TO CARTOGRAPHIC LITERACY THROUGH THE OBJECTS OF LEARNING DECIFRANDO MAPS}

\begin{abstract}
:
When appropriating of the New Information and Communication Technologies (TICs), Geography materializes its contents, through learning objects, as auxiliary instrument of the teaching-learning process, privileging the interactiveness between the pupil and the content. In this sense, this research had as central focus the elaboration of a learning object about cartographic literacy and the validation of it with the subjects of the teaching and learning of Geography. As intrinsic objectives the research, we had: (a) investigating pedagogical practices for the teaching and learning of Geography, through a learning object; (b) developing and executing the learning object in Geography; (c) analyzing the practical application of the learning object in the fifth grade of the Primary School. It is pointed out that, the learning objects, developed in a interdisciplinary and interactive perspective, under a constructive character, come to contribute as practical and viable alternatives, attracting and motivating, with better results in the students' learning, what was proven through the validation of the learning object with the students of fifth grade of the Primary School.
\end{abstract}

Key Words: Information and Communication Technologies; Objects of Learning; Cartographic literacy. 


\section{INTRODUÇÃO}

O atual estágio de desenvolvimento tecnológico, que Milton Santos (1998) denomina de período técnico-científico-informacional, requer significativas transformações nos diversos setores da sociedade, como um pressuposto natural de readaptação à realidade, cada vez mais complexa. No âmbito educacional, a tecnologia vem ao encontro de novas perspectivas que visam dinamizar o processo ensinoaprendizagem através de instrumentos interativos auxiliares. Destaca-se que o processo de melhoria da qualidade do ensino considera, além de outros fatores, a utilização das tecnologias na educação, adotando novas metodologias de ensino e aprendizagem. Nesse sentido, um dos pontos fundamentais em qualquer iniciativa que contemple a introdução de tecnologias na educação é a integração dessas à prática pedagógica. Tal fato requer conhecimento, por parte dos sujeitos da educação, das tecnologias e de suas potencialidades como instrumento didático, além de tê-las disponíveis para sua utilização.

A Geografia, enquanto ciência em processo evolutivo, tem, na visão empírica, na observação, um fator importante para a compreensão da complexa relação sociedade versus natureza. Os conteúdos propostos pela Geografia atrelam teoria e prática como forma eficaz para construir os seus saberes. Por conseguinte, ao se apropriar das Tecnologias da Informação e Comunicação (TICs), essa ciência materializa os seus conteúdos via Objetos de Aprendizagem (OA), privilegiando a interatividade entre o educando e os conteúdos didáticos. O contexto geográfico, particularmente a Cartografia, permite a utilização de meios auxiliares para a compreensão da representação dos diferentes recortes do espaço, utilizando-se da escala mais apropriada para representação dos fenômenos geográficos. Pode-se afirmar então, que a cartografia se fundamenta na leitura e representação do espaço, permitindo, a visualização desse espaço. Nesse contexto, cabe a ela propor desafios, levando o educando a perceber a diversidade espacial na qual está inserido e a possibilidade de analisá-la em escala local, regional, nacional e global. Por meio de mapas e de outros recursos cartográficos ele saberá distinguir os diferentes e distantes locais, possibilitando-lhe uma visão crítica da realidade.

Nessa perspectiva, esta investigação teve como foco central a elaboração de um objeto de aprendizagem sobre a alfabetização cartográfica e sua validação com os sujeitos do ensino e da aprendizagem de Geografia. Como objetivos intrínsecos da pesquisa, tiveram-se: (a) investigar práticas pedagógicas para o ensino e aprendizagem de Geografia, por meio de objeto de aprendizagem; (b) desenvolver e efetivar o objeto de aprendizagem em Geografia; (c) analisar a aplicação prática do objeto de aprendizagem na quinta série do Ensino Fundamental da Escola Estadual de Educação Básica Augusto Ruschi, localizada no município de Santa Maria/RS.

A realização desta pesquisa considerou a relevância da relação ensino-tecnologia para a construção do conhecimento geográfico pelos educadores e educandos, partindo do pressuposto de que os objetos de aprendizagem desenvolvidos em uma perspectiva interdisciplinar e interativa, de caráter construtivista vêm contribuir como alternativa prática e viável, atraindo e motivando, com melhores resultados, à aprendizagem dos alunos. Segundo Vieira (2007), o uso do computador na educação tem como meta promover a aprendizagem dos alunos e auxiliá-los na construção do processo conceitual e no desenvolvimento de habilidades para que ele participe da sociedade do conhecimento e não simplesmente facilitar o seu processo de aprendizagem. 
Assim, o objeto de aprendizagem tem como finalidade primordial auxiliar os sujeitos da educação básica brasileira, fornecendo-lhes subsídios à pesquisa nas áreas do ensino da Geografia, interfaces gráficas, materiais instrucionais e estímulo à informática na educação, tornando tanto o processo de ensinar como o de aprender mais dinâmico e consentâneo com as necessidades educacionais atuais.

\section{MATERIAL E MÉTODOS}

A construção do objeto de aprendizagem de cartografia, realizada no contexto das Tecnologias da Informação e Comunicação (TICs) foi elaborada através de etapas.

Inicialmente, fez-se uma revisão bibliográfica para estabelecer as matrizes teórico-metodológicas da pesquisa. Concomitantemente, foram resgatados os marcos conceituais norteadores da pesquisa, como as TICs, com ênfase para os objetos de aprendizagem, alfabetização cartográfica e mapas mentais em Geografia.

Definido o escopo teórico, partiu-se para a segunda etapa da pesquisa, centrada no desenvolvimento do objeto de aprendizagem, compreendendo todas as fases de sua elaboração, ou seja, desde o primeiro storyboard ${ }^{l}$ até a sua implementação. Desse modo, resgatou-se a construção de mídias, a partir das quais se construiu um acervo de textos e imagens necessários à elaboração do objeto de aprendizagem. De posse desse material, definiram-se os cenários, as ferramentas, o formato do texto, o visual gráfico, as cores, o fluxo de informações e os desafios que fazem parte da multimídia educativa. Dessa forma, pode-se determinar como tratar o erro e o acerto do desafio proposto no objeto de aprendizagem.

A terceira e última etapa diz respeito à validação do objeto de aprendizagem. Nesse sentido, selecionou-se a quinta série do Ensino Fundamental da Escola Estadual de Educação Básica Augusto Ruschi, em conseqüência da introdução do conteúdo cartográfico na sua grade curricular, em que se aborda a alfabetização cartográfica.

A validação foi realizada através da análise de mapas mentais elaborados pelos sujeitos da pesquisa antes e após o uso do OA Decifrando os Mapas. Comparando os mapas em relação à presença e à ausência dos elementos cartográficos, foi possível validar o objeto de aprendizagem. Soma-se a essa avaliação a aplicação de questionários aos alunos. A elaboração dos questionários seguiu a técnica intitulada Técnica de Inspeção de Conformidade Ergonômica de Software Educacional (TICESE), a qual busca estabelecer uma integração entre os critérios ergonômicos de inspeção de usabilidade com critérios pedagógicos para avaliação de software educacional, desenvolvida por Gamez (1999).

\subsection{Metodologia de Desenvolvimento do Objeto de Aprendizagem Decifrando os Mapas}

Esse subitem do artigo justifica-se mediante a necessidade de se especificar as fases de construção do objeto de aprendizagem de forma mais detalhada com o intuito de elucidar os caminhos trilhados na sua construção e operacionalização. Dessa forma, salienta-se:

(a) Linha pedagógica adotada: Utilizou-se, pedagogicamente, o ciclo proposto por Valente (1998), o qual é desencadeado quando se relaciona à construção e à aquisição de novos conhecimentos por parte do aluno, utilizando software educativo. Esse ciclo se

1 O storyboard é um roteiro de aplicação multimídia, o qual se pretende desenvolver (em quadrinhos), em que as ilustrações estão dispostas em seqüência, proporcionando uma produção visual. (WIQUIPÉDIA, 2007). 
apresenta com as seguintes etapas: (a.1) Descrição da resolução do problema; (a.2) Execução dessa descrição pelo computador; (a.3) Reflexão sobre o que foi produzido pelo computador e (a.4) Depuração dos conhecimentos por intermédio da busca de novas informações ou do pensar.

(b) Metodologia tecnológica de desenvolvimento dos objetos: Em consonância com a linha pedagógica, para o desenvolvimento de OA é necessário, seguir algumas etapas, que determinam a metodologia tecnológica adotada. Nesse trabalho, foi utilizada a proposta de Bezerra (2002), a qual classifica as atividades a serem desenvolvidas em: (a) Fase de levantamento de requisitos; (b) Fase de análise e projeto; (c) Fase de implementação; (d) Fase de testes e implantação e (e) Fase de avaliação.

(c) Aplicação prática do objeto de aprendizagem Decifrando Mapas: A construção do objeto de aprendizagem Decifrando Mapas teve sua aplicabilidade na quinta série, turma 54, do Ensino Fundamental da Escola Estadual de Educação Básica Augusto Ruschi. A validação do OA ocorreu no mês de outubro de 2007 , no decorrer de duas semanas letivas, sendo que em cada semana havia três períodos, de 45 minutos, referentes à disciplina de Geografia. O público alvo dessa validação foi de 12 alunos dessa turma, selecionados de acordo com a participação nas atividades do Laboratório de Informática da Escola. Tal pré-requisito era necessário, pois o conhecimento da mesma e da participação nas aulas para a aplicação do objeto de aprendizagem Decifrando Mapas era de vital importância. Salienta-se que a turma 54 é composta por 30 alunos. Assim, a pesquisa procurou abranger aproximadamente $40 \%$ dos mesmos, seguindo os critérios propostos para sua seleção. Ressalta-se que os critérios de amostragem estão baseados na concepção de Minayo (1999), quando o autor enfatiza que a representatividade numérica não se constitui em um critério prévio para a realização da pesquisa qualitativa.

Nesse contexto, aliando os conceitos aos dados coletados e à observação "in loco", pode-se interpretar e analisar a temática em estudo e sua aplicabilidade como instrumento para o ensino de Geografia, com ênfase para o conteúdo da alfabetização cartográfica. Mediante esse esforço teórico e prático, fizeram-se algumas considerações pertinentes às mídias da educação como um instrumento eficaz para o ensino de modo geral e para a Geografia em particular.

\section{RESULTADOS E DISCUSSÃO}

\subsection{Objeto de Aprendizagem: Decifrando os Mapas}

A inserção das TICs nas Escolas, como um instrumento auxiliar do processo ensino-aprendizagem, representa uma inovação nos métodos de construir os saberes. A relação educando-conteúdo ocorre mediante a interação, foco central dessa iniciativa, na medida em que o conhecimento é adquirido através de um pensamento crítico. Ele não deve ser simplesmente "transmitido", mas construído via reflexões.

Considerando-se as TICs, a construção do OA Decifrando os Mapas constituiuse em uma proposta inovadora de construção do conhecimento geográfico, visando a desenvolver habilidades nos alunos no que diz respeito à elaboração de mapas, com ênfase em questões como a visão oblíqua e vertical; imagem bidimensional e tridimensional; os elementos cartográficos (título, orientação, coordenadas e escala) e o alfabeto cartográfico, ou seja, os modos de implantação (ponto, linha e área) nos educandos. Por conseguinte, a literatura enfoca que, para ser um leitor de mapas o aluno 
deve, antes, ser um mapeador, para ter condições de entender e interpretar a linguagem e a visualização cartográfica.

Nesse sentido, a definição da identidade visual do objeto de aprendizagem ocorreu após discussões com profissionais do designer ergonômico e da comunicação visual, privilegiando aspectos como a construção de cenários representativos da cartografia. Para ilustrar o resultado dos esforços desses profissionais atrelado ao conteúdo geográfico proposto, têm-se as três primeiras telas do objeto de aprendizagem, que apresentam, respectivamente, a identidade visual e o nome do mesmo; a motivação do aluno para a interação com o objeto de aprendizagem e a apresentação do desafio de decifrar os mapas através da elaboração de mapas do município de Rivedlândia.

A proposta dessa tela centra-se na especificação do tipo de desafio proposto ao educando: ser um mapeador e, conseqüentemente, um leitor de mapas. Pode-se observar que, a partir dessas telas o aluno interage com o objeto, podendo prosseguir para as telas posteriores, ou retornar para a anterior, caso haja necessidade.

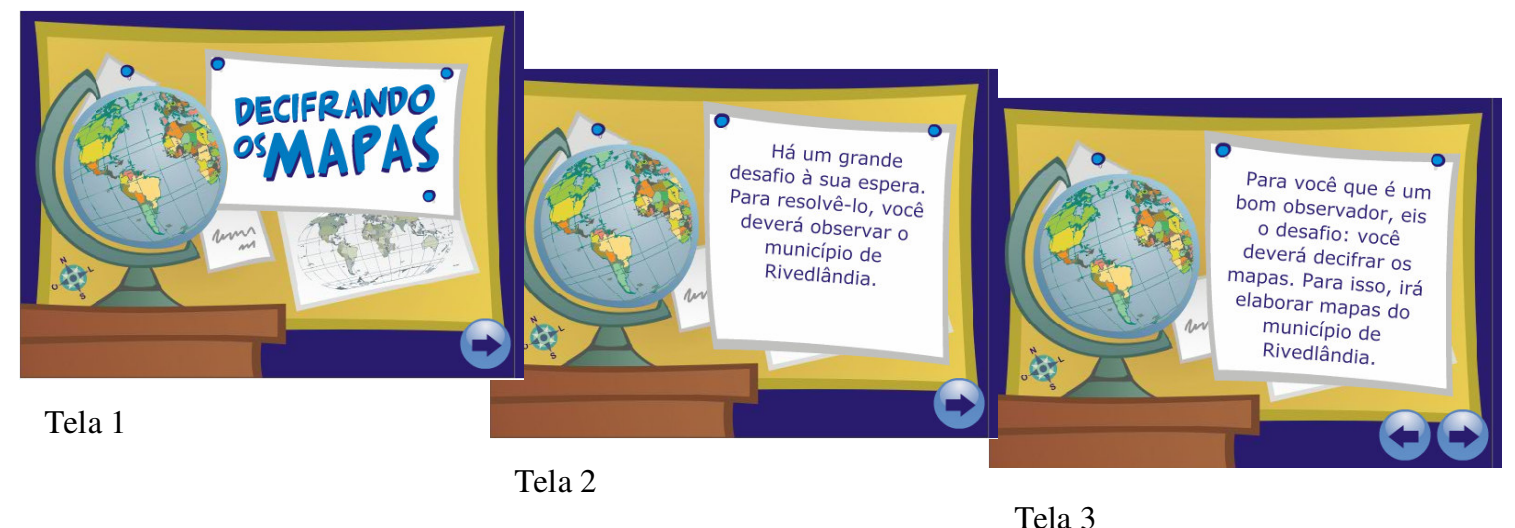

Da tela 4 até a 6, têm-se as visões cartográficas para a definiçãa da visão em que serão elaborados os mapas. $\mathrm{Na}$ tela 4 , apresenta-se a visão vertical, característica essencial da alfabetização cartográfica. As telas que apresentam as visões cartográficas proporcionam as distintas formas de visualização obtidas e os elementos cartográficos contidos em um mapeamento. Para o aluno observador, essas particularidades tornaramse essenciais para que ele selecione o tipo de visão adotada nessa proposta de mapeamento interativa. Paralelamente, procurou-se demonstrar a representatividade do espaço quanto aos seus elementos constituintes nas diferentes visões, tendo como base a mesma paisagem, composta por casas, ruas, trilhos, árvores e um rio, dentre outros aspectos. Salienta-se que, o tipo de visão, altera a representatividade dos objetos no desenho, fazendo com que, na visão vertical, se obtenha uma homogeneidade quanto à representação, variando o tamanho de acordo com a proporção entre os mesmos. De modo geral, na visão vertical, os mapas proporcionam uma visão completa do terreno a ser mapeado, guardando a diferenciação entre o tamanho de cada objeto. As telas representativas das visões cartográficas foram observadas pelos alunos na validação do AO Decifrando os Mapas. Pode-se afirmar que o OA, atingiu o objetivo proposto, o qual aliava teoria à prática, uma vez que, os educandos puderam identificar a visão mais adequada para se realizar um mapeamento, ou seja, a visão vertical. 


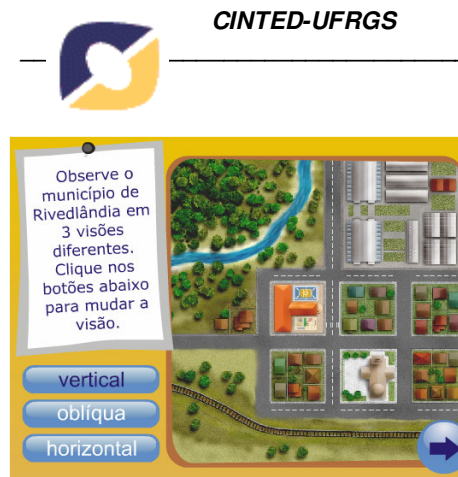

Tela 4

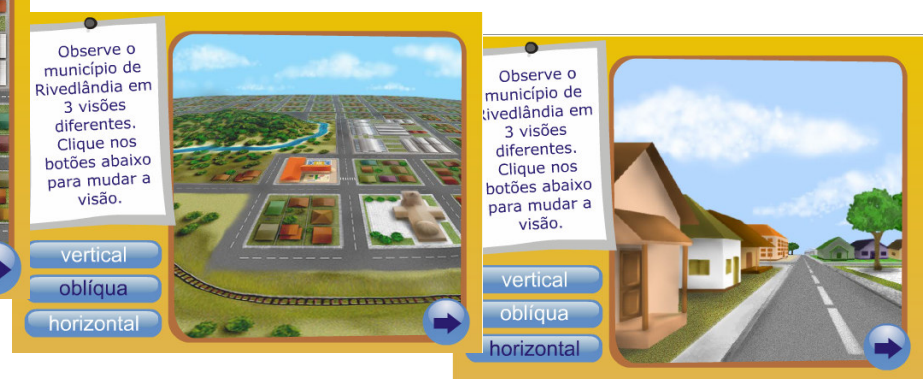

Tela 6

Na tela 7, a interatividade é desencadeada através do estímulo a escolha do tipo de visão para elaborar o mapa.

Essa tela atesta a necessidade do conhecimento teórico atrelado à prática, proporcionada pela validação do objeto de aprendizagem, uma vez que, constitui-se em uma consequiência das telas anteriores, ou seja, é mister que o educando tenha a compreensão do conteúdo associado.

Nas telas 8 e 9, trabalha-se o erro e o acerto, referentes à escolha do tipo de visão para elaborar os mapas. Ressalta-se que, pedagogicamente, essa

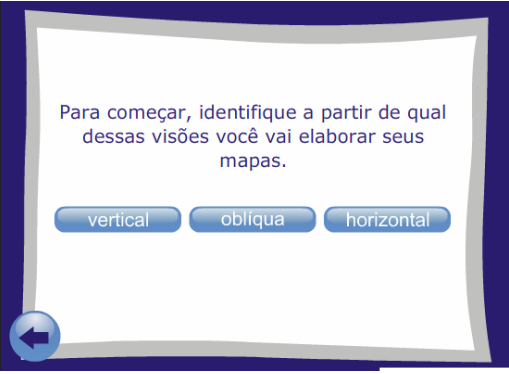

Tela 7 abordagem constitui um desafio na elaboração do objeto de aprendizagem.

$\mathrm{Na}$ medida em que o aluno optou pela escolha correta, pode observar a mensagem que exprime o acerto e, também, uma informação relativa à confecção dos mapas e à importância da visão vertical na Cartografia.

Tela 8

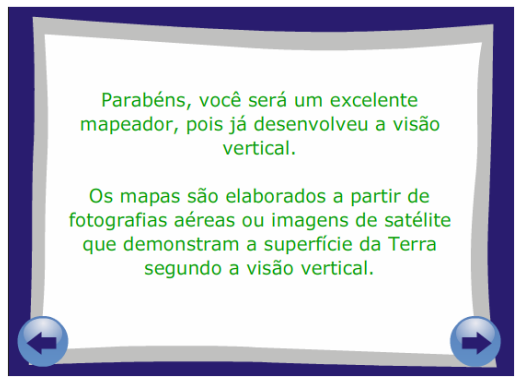

No decorrer do desenvolvimento da interação entre os alunos e o OA Decifrando os Mapas, a tela 10 apresenta as características bidimensional e tridimensional. Essa tela demonstra, sobretudo, que as representações possuem largura e altura, ou largura e comprimento, configurando-se como as representações bidimensionais, com exceção das maquetes que são tridimensionais, pois através da redução representa-se a altura, a largura e o comprimento de um objeto.

As telas 11 e 12 constituem algumas opções de esclarecimento auxiliar ao conteúdo teórico

\section{Opa!}

Os mapas são elaborados a partir de fotografias aéreas ou imagens de satélite que demonstram a superfície da Terra.

Analise as visões e tente novamente.

Tela 9

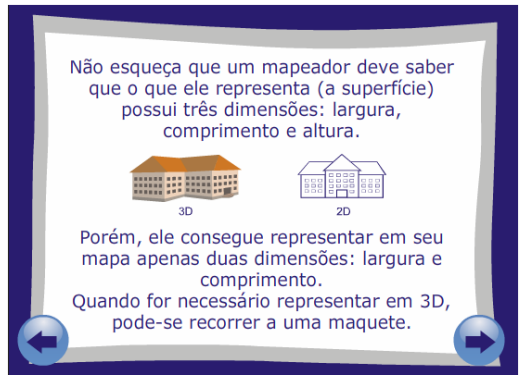

Tela 10 
trabalhado em sala de aula referente ao conhecimento dos modos de implantação. Dessa forma, na tela 11 há um link com a opção de escolha do modo de implantação a partir do qual o aluno irá elaborar o mapa.
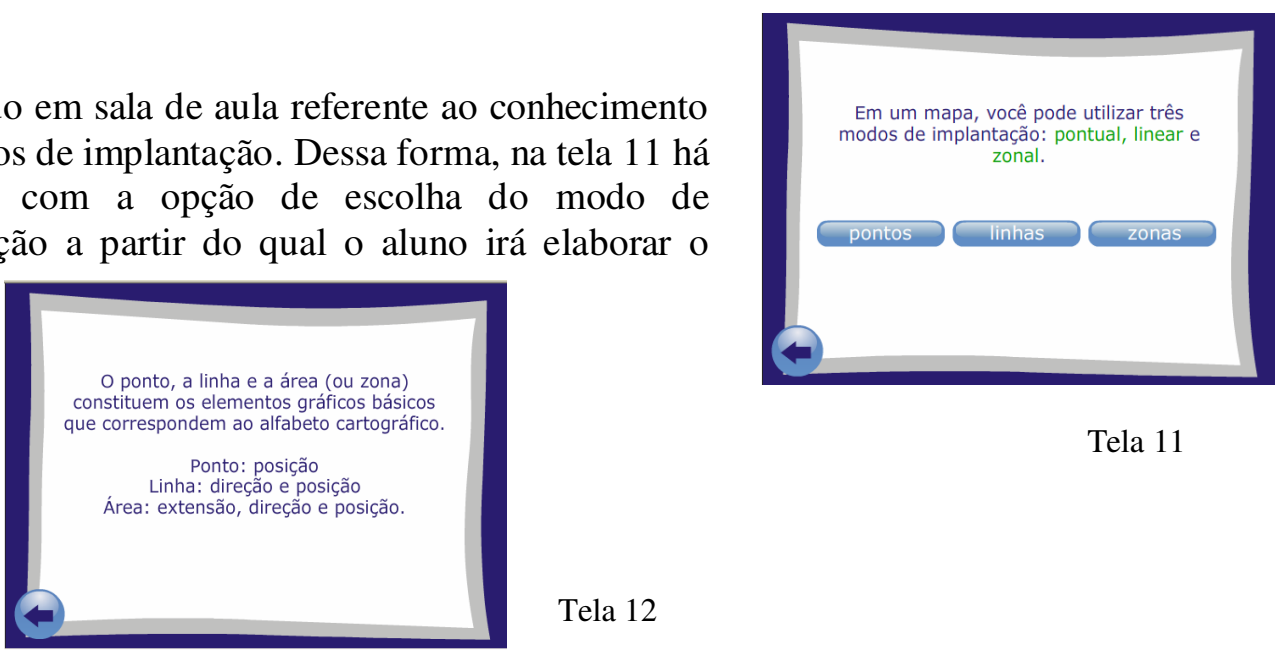

Tela 11

Tela 12

Os modos de implantação são apresentados na tela 12, ao mapeador, de acordo com a opção de escolha mediante o objetivo da confecção do seu mapa. Para tanto, a tela 12 expõe o embasamento teórico referente a esses modos de implantação, para elucidar o aluno diante da escolha a se realizar, ou seja, permite que o mesmo faça um resgate teórico da fundamentação obtida nas aulas expositivas. Na tela 13, apresentam-se os elementos cartográficos para o aluno elaborar o mapa. Desse modo, essa tela representa a interface essencial do OA. A mesma demonstra os elementos cartográficos essenciais para um mapeamento, pois se refere ao entendimento da representação. A colocação, desses elementos, de forma correta é o fator primordial para a leitura do mapa, em função do seu entendimento no que se refere às informações nele presentes.

Nas telas seguintes, da tela 14 à tela 18 , o aluno tem a visualização dos elementos cartográficos, os quais objetivam embasar sua escolha. Nesse sentido, o OA Decifrando os Mapas procurou alicerçar o resgate conceitual dos principais aspectos relativos à alfabetização cartográfica, para que o aluno pudesse rever o conteúdo construído nas aulas expositivas e prosseguir com o exercício proposto por esse objeto de aprendizagem.

$\mathrm{Na}$ medida em que se alia teoria e prática, viabiliza-se $\mathrm{o}$ aprendizado de forma efetiva e gradual, resgatando-o a cada etapa da construção de um mapeamento cartográfico, para que ele contenha os elementos fundamentais para tal exercício.

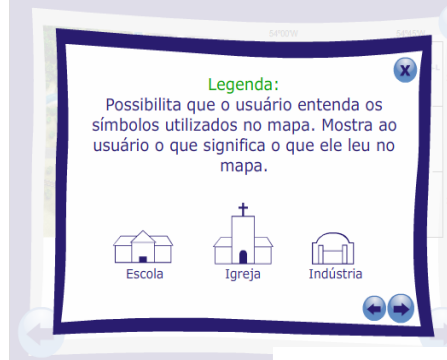

Tela 18

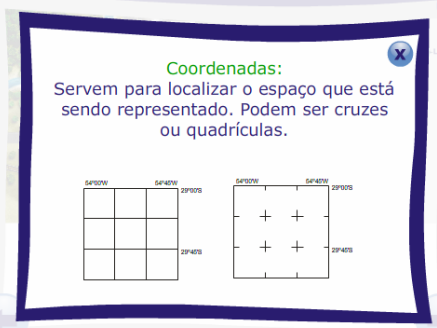

Tela 17

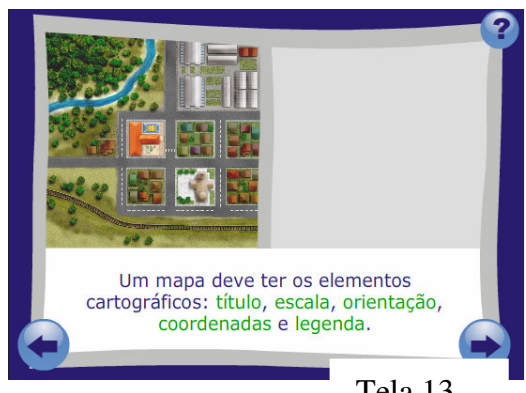

Tela 13

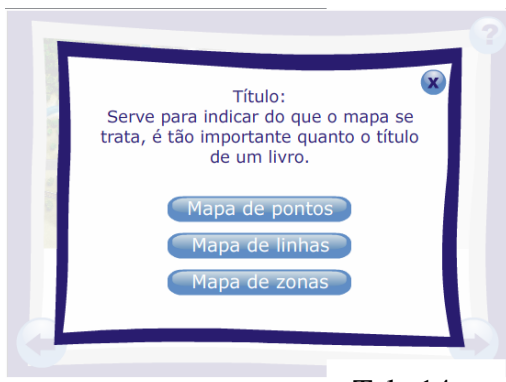

Tela 14

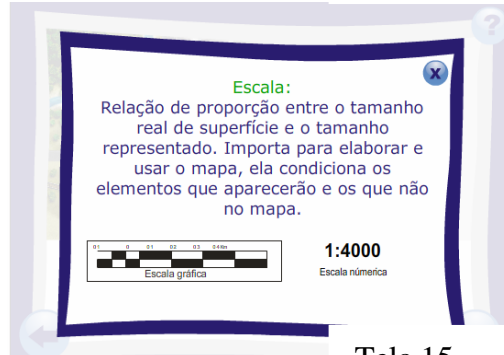

Tela 15

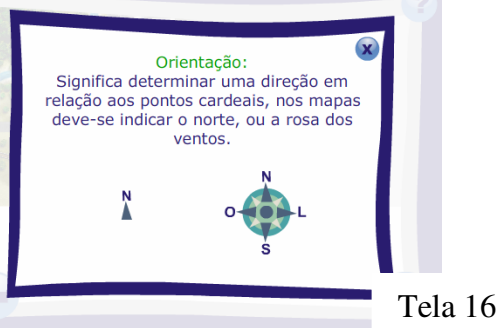


$\mathrm{Na}$ tela 19, apresenta-se uma das possibilidades de mapa que o aluno poderá elaborar. Destaca-se a reusabilidade do objeto de aprendizagem, que se deriva da utilização de programação orientada a objetos, a qual permite que parte, ou módulos inteiros, sejam reaproveitados na produção e/ou adaptação de novos programas. A reutilização pode readaptar atividades para diferentes tipos de usuários.

$\mathrm{Na}$ tela 20, finaliza-se o objeto de aprendizagem apontando aplicações práticas, como a leitura de mapas. Há um botão de reiniciar, que pode ser usado para reutilizar o OA Decifrando os Mapas. Essa tela representa a etapa final, na qual é apresentada uma representação cartográfica, em que se explica a possibilidade de temáticas a serem confeccionadas, enfatizando o espaço vivido pelos

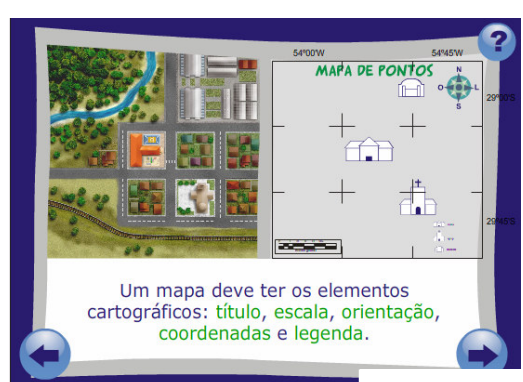

Tela 19 educandos.

Além de desenvolver as habilidades de leitura e interpretação de informações contidas nos mapas com temáticas diversificadas, o AO atua como forma de exercitar os conhecimentos cartográficos construídos nas aulas de Geografia. Observa-se a reusabilidade do Decifrando os Mapas de acordo com as necessidades dos educandos em realizar os exercícios propostos em Cartografia, como conteúdo básico para o aprendizado dessa disciplina.

\subsection{Elementos Cartográficos em Mapas Mentais para avaliação/ validação do Objeto de Aprendizagem Decifrando os Mapas}

A validação do OA representa identificar sua eficácia quanto instrumento de ensino. Para a validação do OA Decifrando os Mapas, utilizou-se as fases anterior e posterior ao seu uso. Assim, procurou-se comparar a aplicação dos elementos cartográficos utilizados mapas mentais realizados pelos alunos, anteriormente, ao uso do objeto de aprendizagem e, após sua utilização. Desse modo, pôde-se analisar a presença ou ausência dos elementos cartográficos nos mapas mentais, o que indicou a apreensão cartográfica gerada pelo OA.

Com relação ao elemento cartográfico título observa-se que o OA Decifrando os Mapas foi essencial, uma vez que a aplicação do título nos mapas mentais elaborados pelos alunos, após o uso do OA foi significativamente maior do que nos mapas mentais construídos anteriormente à utilização do $\mathrm{OA}$.

A escala, outro elemento cartográfico fundamental, não apresentou índices tão satisfatórios quanto os obtidos com o título. Observa-se que esse elemento implica um exercício abstrato que pode gerar uma sobrecarga cognitiva em relação aos estágios de desenvolvimento dos alunos, pois a escala constitui-se em um exercício com maior nível de dificuldade de apreensão em relação aos outros elementos cartográficos.

No que se refere às coordenadas geográficas, essas se constituíram em um elemento cartográfico que exigiu grande apreensão por parte dos alunos, pois os mesmos tiveram de resgatar noções teóricas relativas a esse elemento para realizar a prática. Destaca-se que, para aplicar as coordenadas no mapeamento realizado, os alunos colocaram coordenadas fictícias, pois o objetivo centrou-se na composição correta dos elementos contidos no mapa. 
No que diz respeito à orientação, pode-se constatar que esse foi um dos elementos mais empregados pelos alunos após o uso do Decifrando os Mapas, devido à apreensão em relação à fundamentação teórica e sua aplicação prática, identificando o norte geográfico em relação as suas representações. Para explicitar a temática da orientação utilizou-se a fundamentação teórica referente a essa parte do conteúdo, com noções de orientação em relação ao nascente e ao poente do sol e o estabelecimento de pontos referenciais para se memorizar o norte.

A legenda foi um dos elementos mais empregados após o uso do objeto de aprendizagem Decifrando os Mapas, uma vez que se procurou ressaltar a importância desse elemento cartográfico e, pelo mesmo, informar o significado de cada objeto representado. Por sua vez, a legenda demonstrou a criatividade dos educandos em relação à representação cartográfica, em que cada aluno utilizou-se de formas típicas próprias apreendidas em seu espaço vivido. A aplicação da legenda demonstra, também, a capacidade de percepção em relação à composição do espaço referente ao trajeto proposto para confeccionar os mapas mentais.

Em relação à visão vertical destaca-se que o Decifrando os Mapas, despertou tal característica na elaboração dos mapas após seu uso, uma vez que, a visão vertical não gera distorções, pois é a mais fidedigna na representação do espaço geográfico.

Chama-se atenção, para algumas questões verificadas após a aplicação do questionário aos alunos, entre as quais, a preferência por atividades desenvolvidas no laboratório de informática, como o uso do computador e da aplicação do OA Decifrando os Mapas, em detrimento ao uso do livro didático.

Pode-se destacar a usabilidade, a qual se refere à facilidade de navegação e clareza das informações, para que a exploração do objeto seja simples para o usuário. Neste aspecto a maioria dos educandos considerou o OA de fácil navegação, podendo assim ser útil no seu aprendizado de Geografia. Por conseguinte, na opinião dos alunos, o objeto de aprendizagem foi considerado válido para a construção do conhecimento, por ser uma atividade prática e interativa, que direcionou sua atenção para a atividade proposta. (TRABALHO DE CAMPO, 2007).

\section{CONCLUSÕES}

As TICs constituem-se na introdução de tecnologias na educação, objetivando alicerçar o desenvolvimento e a melhoria da qualidade do ensino, através de instrumentos interativos que auxiliem no processo ensino-aprendizagem. Desse modo, torna-se necessário integrar as mídias da educação às práticas pedagógicas para a elaboração de instrumentos didáticos, referentes aos conteúdos propostos, seja no Ensino Fundamental, Médio ou Superior. Na perspectiva das TICs, os objetos de aprendizagem materializam-se como softwares interativos que viabilizam a construção da aprendizagem mediante a investigação realizada pelo educando, instigando-o a apreender o conteúdo proposto, como agente ativo na construção do mesmo.

Pode-se afirmar também que os objetos de aprendizagem proporcionam, aos alunos, a inclusão digital, via salas de informática, nas quais se desenvolvem as atividades práticas relativas à validação dos objetos. $\mathrm{O}$ acesso à informática constitui-se em uma barreira socioeconômica para os educandos. Sabe-se que os alunos que estudam em escolas públicas, em sua maioria, não têm acesso à mesma em seus lares. Neste sentido, o papel da escola, é o de minimizar tal carência, via laboratórios de informática, com recursos pedagógicos apropriados para a construção do conhecimento, como os OA. 
$\mathrm{Na}$ era das tecnologias avançadas, a Geografia se insere na vanguarda do uso das técnicas, pois é uma ciência que se apropria das mesmas para atingir os objetivos propostos intrínsecos as suas linhas de pesquisa. Nessa perspectiva, destacam-se as inovações tecnológicas como agentes dinamizadores dessa ciência, pois a adaptam a realidade global, sua escala máxima de análise. Também permite acompanhar, paralelamente, o aperfeiçoamento dos conhecimentos mediados pela técnica, como um instrumento eficaz e auxiliar na realização de suas pesquisas. Ao se considerar as diretrizes das TICs, os objetos de aprendizagem vêm ao encontro das licenciaturas, de um modo geral e, principalmente, da Geografia, uma vez que proporciona a construção de uma mídia interativa que atrela teoria e prática, para o ensino de Geografia nos distintos níveis da educação.

No contexto das TICs, aplicadas a Geografia, o objeto de aprendizagem Decifrando os Mapas configurou-se como um instrumento auxiliar para o ensino da cartografia na quinta série do Ensino Fundamental. Esse conteúdo é basilar para o aprendizado geográfico, principalmente por apresentar os principais elementos que compõem um mapa e, também, por enfocar questões referentes à orientação espacial. Considerando que o aluno, antes mesmo de ser um leitor de mapas, torna-se um mapeador, afirma-se a importância da alfabetização cartográfica como conteúdo básico no contexto geográfico. Pode-se comprovar tal afirmação através da validação do OA Decifrando os Mapas, via experiência prática realizada no decorrer do trabalho de campo.

Para a Geografia, as TICs tornam-se fundamentais para auxiliá-la na compreensão dos conteúdos. A complexidade do objeto de estudo da Geografia, centrado na interface sociedade-natureza, possibilita inúmeras propostas de desenvolvimento de objetos de aprendizagem, nas diversas linhas temáticas inerentes à ciência geográfica.

\section{REFERÊNCIAS BIBLIOGRÁFICAS}

ARCHELA, R. S.; GRATÃO, L. H.; TROSTDORF, M. A. S. O lugar dos mapas mentais na representação do lugar. Geografia, Londrina, v. 13, n. 1, jan./jun., 2004.

BEZERRA, E. Princípios de análise e projeto de sistemas com UML. Rio de Janeiro: Campus, 2002.

DOWBOR, L. Tecnologias do Conhecimento. Rio de Janeiro: Vozes, 2001.

GAMEZ, L. Técnica de Inspeção de Conformidades Ergonômicas em Software Educacional. TICESE -1998. 250 f. Dissertação de Mestrado. Universidade do Minho. Guimarães. Portugal, 1998.

MINAYAO, M. C. O Desafio do Conhecimento: Pesquisa Qualitativa em Saúde. 6 ed.São Paulo: HUCITEC-ABRASCO, 1999.

SANTOS, M. Técnica, espaço, tempo: globalização e meio técnico-científicoinformacional. São Paulo: HUCITEC, 1994.

VALENTE, J. A. O computador na sociedade do conhecimento. Campinas: NIED, 1999.

VIEIRA, F. M. S. Avaliação de Software Educativo: Reflexões para uma Análise Criteriosa. Disponível em: <http://edutec.net/Textos/Alia/MISC/edmagali2.htm>. Acesso em: 15 ago. 2007.

WILEY, D. A. Connecting learning objects to instructional design theory: a definition, a metaphor and a taxonomy. Disponível em <http: //www.reusabilitty.org/read/chapters>. Acesso em: 01 ago. 2006. 